\title{
Application of Fuzzy Analytic Hierarchy Process in Ranking Modern Educational Systems' Success Criteria
}

\author{
Mohammad Reza Mehregan, Mona Jamporazmey, Mahnaz Hosseinzadeh, and Mohsen Mehrafrouz
}

\begin{abstract}
-by advancing information and communication technology (ICT), e-learning has emerged as a modern educational paradigm. This online learning environment improves the delivery of teaching content, knowledge sharing among trainees, social interaction and so forth. Regarding mass investment for e-learning solutions which don't meet their original objectives, e-learning performance assessment remains crucial. E-learning appraisal assists managers of educational institutes by revealing weak and strength aspects of these initiatives and creates opportunity to improve and make effective e-learning systems.

This paper aim is to introduce a new approach to e-learning system assessment by identifying and prioritizing the preliminary e-learning critical success factors (CSFs) or enablers that need to be concentrated by universities and educational institutes. The result of such performance evaluation subsequently acts as an informative tool for developing e-learning systems plan.
\end{abstract}

Index Terms-E-learning, Critical Success Factors (CSF), Fuzzy analytic hierarchy Process (FAHP).

\section{INTRODUCTION}

In the recent years, the interest in e-learning tools, designing and implementing e-learning methods has been increased [1]. These systems allow people for "learning far away", and they have been frequently designed and used in higher education [1].

Information technology (IT) is playing an important role in recent educational evolution via providing more efficient, effective and modern way of student learning, IT has been viewed as a solution for cost and quality issues of universities [2]. The main reasons of rapid growth of e-learning can be summarized as follows: an opportunity for overcoming the limitations of traditional learning, such as geographical distance, time, budget or busy program; equal opportunities

For getting education no matter where you live, how old you are, better quality and a variety of lecture materials; use shared resources and the students can receive knowledge, skills and experience from other universities [1] -learning has

Manuscript received October 11, 2011; revised October 27, 2011

Mohammad Reza Mehregan is an associate Professor with Department of Industrial Management, Faculty Management, University of Tehran, Tehran, Iran (E-mail: mehregan@ut.ac.ir).

Mona Jamporazmeyr is a Phd candidate of Information System Management,Department of Information Technology Management, Faculty of Management,University of Tehran, Tehran, Iran (monajami@ut.ac.ir)

Mahnaz Hosseinzadeh is a PhD Candidate in Operation Research, with Department of Industrial Management, Faculty of Management, University of Tehran, Tehran, Iran (E-mail: mhosseinzadeh@ut.ac.ir)

Mohsen Mehrafrouz. is MA of public administration, Azad University, Naragh, Iran (Mehrafrouz@yahoo.com). been viewed as the use of the Information and Communication Technologies (ICT) to improve the quality of learning by facilitating access to resources and services, as well as remote exchanges and collaboration [2]

These e-learning systems gather a huge deal of information; which is worthy in evaluating students, performance and assisting teachers to detect of possible errors, shortcomings and finally get improvements [1]

Worldwide, the e-learning market has a growth rate of $35.6 \%$, but failures exist [1]. Although some researchers believe e-learning students learn as well as students of traditional methods, e-learning courses have some limitations which must be reveal and amend [1]. For instant, many online courses cannot sufficiently motivate students to participate, in other word, web based education (e-learning) is apt to isolate trainees and this feature lead to high rate of failure. By considering increasing investment on e-learning solutions, it is important to know how evaluate e-learning programs and overcome their shortcomings [1]. Many researchers have studied several aspects of e-learning and many different approaches were adopted to assess e-learning performance and outcomes [1], [1], [2].

As Strand \& Thune [1] notify that evaluation process answers questions such as: Are new technologies producing better learning than traditional classrooms and traditional teachers? Or, are claims of radical improvements in learning as a result of ICT only empty words aimed at making people believe in the utility of ICT and buy more technology? The costly high failure rate of e-learning implementations [6], [1] and some perceived deficiencies of e-Learning [7] make performance evaluation of e-learning as a crucial issue.

One way of facing these challenges is identifying critical success factors of e-learning. Implementing CSFs is vital to achieve success. Critical Success Factors (CSF) entitle something which must be implemented if companies want to be successful. These factors should be controllable and measurable and also few in number [3]. The factors affecting e-learning performance presented by previous studies are basically focused on certain perspectives [6], [12]. This paper has two main contributions: first, proposing a comprehensive approach for assessing e-learning initiatives by using CSF methodology and FAHP method and second, prioritizing the importance of each CSF from e-Learner's viewpoints. To get these aims, the paper combines tow well known managerial methodologies, fuzzy AHP and critical success factors.

The analytic hierarchy process (AHP) is one of the most widely used multiple-criteria decision-making (MCDM) methods. Because of the uncertainty and vagueness as well as imprecision of human decision making in daily life decisions, a fuzzy AHP (FAHP) is used to add with the CSF.

The remainder of the paper is organized as follows: 
Section 2, briefly reviews CSF and fuzzy AHP literature. Section 3, introduces research methodology and data collection. In section 4 , the gathered data is analyzed. In section 5, conclusion extracted from survey is argued.

\section{BACKGROUND}

\section{A. Definition of e-learning}

Recent studies expose that yearly organizations approximately spend 40 billion dollars on e-learning and other technology-based learning programs. Furthermore, more than three million students registered in web based learning courses and large companies saved million dollars yearly [8]. E-learning is a new educational trend and also a challenge for traditional learning. E-learning has been viewed synonymous with web-based learning (WBL), online learning, advanced distributed learning, open/flexible learning, internet-based learning (IBL) [8]. Volery and Lord [1] define e-learning as a combination of learner, faculty, instructor, technical staff, administrative, learner support, and use of the Internet and other technologies. E-learning can be defined as learning initiatives which offer educational materials through online repositories where course interactions and communications are technology mediated [8]. Keramati et al. [1] consider e-learning as a new method of training which complements traditional methods and its final ambition is to build an advanced society for citizens and support creativity and innovation. Martinez-Torres et al. [2] asserte that Multimedia tools, web educational environments, simulation environments, and the distance education have turned into viable educational methodologies, increasing flexibility, accessibility, adaptability, and eliminating the spatial and temporary restrictions of the educational process

E-learning has two aspects: The first aspect is related to structural issues (technology, learning process, learning design) and the other one is related to communicational issues (trainees habits, skills and communication patterns) [7].

\section{B. E-learning Critical Success Factor (ECSF)}

Issues related to efficiency, effectiveness and cost are as a driver force for organizations and universities to implement e-learning initiatives [1]. E-learning as an application of IT is integrated with many universities programs [3]. By corresponding, considerable e-learning growth, many researchers from psychology and information system fields have identified important variables dealing with e-Learning success [6]. For instance Thurmond et al [1] introduced some factors which affect e-trainee satisfaction namely Computer skills, courses taken, initial knowledge about e-learning technology, live from the main campus of the institution, age, receive comments in a timely manner, offer various assessment methods, time to spend, scheduled discussions, team work, acquaintance with the instructors. Lau \& Tsui [1] declare that knowledge management can enhance e-learning effectiveness. Knowledge management tools such as community, social software, peer-to-peer and personalized knowledge management are now commonly being used in ubiquitous learning. Learners use these tools to generate and share ideas, explore their thinking, and acquire knowledge from other learners.
The rationale behind of e-learning initiatives, like any other learning approach, is to realize the learning objectives. The success criteria of e-learning measures can be environmental, technological, student related, and instructor related [11]. In e-learning some of CSFs are related to technological issues like board band width, reliability of hardware, accessibility, network security, and another success factor is the level of trainees participation and other success factor is related to trainee characteristics like student' commitment and motivation and also their learning speed [3]. Soong et al. [1] use some case studies to identify e-learning CSF and they assert that human factors, technological skill of instructor and student, instructor's attitude and student's attitude to e-learning degree of collaboration, IT infrastructure are most important factors to e-learning success. Picoli et al.[1] site individual features of trainee such as maturity and ability to work with computer and design/technology features such as reliability of technology and individual interactions have significant effects on e-learning effectiveness. According to the studies of Picoli et al [18], Johnson et al [8] also highlight the importance of interacting and participating educational environment and mention trainees features and technology have influence on e-learning outcomes. Table (1) shows briefly some studies about e-learning CSFs.

Based on comprehensive study by Mosakhani and Jamporazmey [7], this paper groups CSFs of e-learning in to seven categories. CSFs and their related indicators are mentioned as following: Instructor characteristics (Instructor attitude to student, Instructor attitude to e-learning, Computer skill), Student characteristics (Computer skill, motivation, commitment, learning speed), Content quality (Updated content, sufficient content, understandable content), Information technology quality (reliability, accessibility, degree of guidance, design of user interface, network security, and timeliness), Participations Interaction (Learning community, ease of interaction with together), Educational institutes support (Providing financial support, proper feedback, diversity evaluation methods) and Knowledge management (Degree of applying knowledge management tools).

\section{Fuzzy Set Theory}

Fuzzy Set Theory was first introduced by Bellman and Zadeh in 1965 to deal with the uncertainty and vagueness as well as imprecision of human decision making in daily life decisions [1].

The characteristic function $\mu_{\mathrm{A}}$ of a crisp set $\mathrm{A} \subseteq \mathrm{X}$ assigns a value either 0 or 1 to each member in $X$. This function $\mu_{\widetilde{A}}$ can be generalized to a function such that the value assigned to the element of the universal set $\mathrm{X}$ fall within a specified range i.e $\mu_{\widetilde{A}}: X \rightarrow[0,1]$ The assigned value indicate the membership grade of the element in the set $A$.

The function $\mu_{\widetilde{\mathrm{A}}}$ is called the membership function and the set $\widetilde{A}=\left\{\left(x, \mu_{\widetilde{A}}(x)\right) ; x \in X\right\}$ defined by $\mu_{\widetilde{A}}(x)$ for each $x \in X$ is called a fuzzy set [1].

A fuzzy number is said to be a triangular fuzzy number if Its membership function is given as 
TABLE I: SOME OF E-LEARNING CSF STUDIES

\begin{tabular}{|c|c|}
\hline Author(s) & Critical Success Factors \\
\hline Dillon and Guawardena [2] & technology, instructor characteristics, student characteristics \\
\hline Volery and Lord [13] & Technology, instructor, previous use of technology from student's perspective \\
\hline Soong et al [17] & $\begin{array}{l}\text { Human factors, teacher and student s technical competency, attitude of teacher and student about } \\
\text { e learning courses, cooperation level, IT infrastructure }\end{array}$ \\
\hline Govindasamy [2] & $\begin{array}{l}\text { Institutional support, course development, teaching and learning, course structure, student } \\
\text { support, faculty support, and evaluation and assessment }\end{array}$ \\
\hline Selim [3] & Instructor, student, information technology, and university support \\
\hline Shee \& Wang [2] & Learner interface, learner community, system content, personalization \\
\hline Sun et al [6] & $\begin{array}{l}\text { Learner dimension, Instructor dimension, Course dimension, Technology dimension, Design } \\
\text { dimension, Environmental dimension }\end{array}$ \\
\hline Ozkan \& Koseler [12] & $\begin{array}{l}\text { System quality, service quality, content quality, learner perspective, instructor attitudes, } \\
\text { supportive issues }\end{array}$ \\
\hline Mosakhani \& Jamporazmey [7] & $\begin{array}{l}\text { Instructor characteristics, Student characteristics, Content quality, Information technology } \\
\text { quality, Participations Interaction, Educational institutes support, Knowledge management }\end{array}$ \\
\hline
\end{tabular}

$$
\mu_{\widetilde{M}}(x)=\left\{\begin{array}{lc}
\frac{x-l}{m-l} & l \leq x \leq m \\
\frac{u-x}{u-m} & m \leq x \leq u \\
0 & \text { otherwise }
\end{array}\right.
$$

Consider two triangular fuzzy number $M_{1}$ and $M_{2}$, $M_{1}=\left(l_{1}, m_{1}, u_{1}\right)$ and $M_{2}=\left(l_{2}, m_{2}, u_{2}\right)$. The arithmetic operations between the two triangular fuzzy numbers are defined as follows [2]:

$$
\begin{aligned}
& \left(l_{1}, m_{1}, u_{1}\right) \oplus\left(l_{2}, m_{2}, u_{2}\right)=\left(l_{1}+l_{2}, m_{1}+m_{2}, u_{1}+u_{2}\right) \\
& \left(l_{1}, m_{1}, u_{1}\right) \otimes\left(l_{2}, m_{2}, u_{2}\right)=\left(l_{1} l_{2}, m_{1} m_{2}, u_{1} u_{2}\right) \\
& \left(l_{1}, m_{1}, u_{1}\right)^{-1}=\left(\frac{1}{u_{1}}, \frac{1}{m_{1}}, \frac{1}{l_{1}}\right)
\end{aligned}
$$

The analytic hierarchy process, which first proposed by Saaty [2], (AHP) is a decision making approach that considers both qualitative and quantitative data and combines them by decomposing ill-structured problems into systematic hierarchies to rank alternatives based on a number of criteria. This approach has become one of the most widely used multiple-criteria decision-making (MCDM) methods because it provides a proven, effective means for dealing with complex systems related to making a choice, enables the decision-maker to incorporate subjectivity, experience, and knowledge into the decision process in an intuitive and natural way and computes the weight for each criterion and the final weighted average score for each alternative. Since fuzziness and vagueness are common characteristics in many decision-making problems, a fuzzy AHP (FAHP) is used as a complement approach of CSF to develop the framework of prioritizing e-learning systems.

\section{Methodology of FAHP}

Let $X=\left\{x_{1}, x_{2}, \ldots, x_{n}\right\}$ be an object set, and $U=$ $\left\{u_{1}, u_{2}, \ldots, u_{n}\right\}$ be a goal set, According to the method of Chang's [2] extent analysis, each object is taken and extent analysis for each goal, $\mathrm{g}_{\mathrm{i}}$ is performed, respectively. Therefore, $m$ extent analysis values for each object can be obtained, with the following signs

$$
M_{g_{i}}^{1}, M_{g_{i}}^{2}, \ldots, M_{g_{i}}^{m} \quad i=1,2, \ldots, n
$$

where all $M_{g_{i}}^{j}, j=1, \ldots, m$ are fuzzy triangular numbers.

The steps of Chang`s [23] are briefly represented bellow:

Step 1: The value of fuzzy synthetic extent with respect to the ith object is defined as

$$
s_{i}=\sum_{j=1}^{m} M_{g_{i}}^{j} \otimes\left[\sum_{i=1}^{n} \sum_{j=1}^{m} M_{g_{i}}^{j}\right]^{-1}
$$

where:

$$
\sum_{j=1}^{m} M_{g_{i}}^{j}=\left(\sum_{j=1}^{m} l_{i}, \sum_{j=1}^{m} m_{i}, \sum_{j=1}^{m} u_{i}\right)
$$

$$
\begin{array}{r}
\sum_{i=1}^{n} \sum_{j=1}^{m} M_{g_{i}}^{j}= \\
\left(\sum_{i=1}^{n} \sum_{j=1}^{m} l_{i}, \sum_{i=1}^{n} \sum_{j=1}^{m} m_{i}, \sum_{i=1}^{n} \sum_{j=1}^{m} u_{i}\right),
\end{array}
$$

And

$$
\begin{aligned}
& {\left[\sum_{i=1}^{n} \sum_{j=1}^{m} M_{g_{i}}^{j}\right]^{-1}} \\
& =\left(\frac{1}{\sum_{i=1}^{n} \sum_{j=1}^{m} u_{i}}, \frac{1}{\sum_{i=1}^{n} \sum_{j=1}^{m} m_{i}}, \frac{1}{\sum_{i=1}^{n} \sum_{j=1}^{m} l_{i}}\right)
\end{aligned}
$$

Step2: the degree of possibility of $\mathrm{M}_{1} \geq \mathrm{M}_{2}$ is defined as 


$$
V\left(M_{1} \geq M_{2}\right)=\underbrace{\sup }_{\mathrm{x} \geq \mathrm{y}}\left[\min \left(\mu_{M_{1}}(x), \mu_{M_{2}}(y)\right)\right]
$$

Since $\mathrm{M}_{1}$ and $\mathrm{M}_{2}$ are convex fuzzy numbers, then

$$
\begin{aligned}
& V\left(M_{1} \geq M_{2}\right)=1 \quad \text { if } m_{1} \geq m_{2}, \\
& V\left(M_{2} \geq M_{1}\right)=\operatorname{hgt}\left(M_{1} \cap M_{2}\right)=\frac{l_{1}-u_{2}}{\left(m_{2}-u_{2}\right)-\left(m_{1}-l_{1}\right)}
\end{aligned}
$$

To compare M1 and M2, we need both the values of

and

$$
V\left(M_{1} \geq M_{2}\right)
$$

$$
V\left(M_{2} \geq M_{1}\right) .
$$

Step3: The degree possibility for a convex fuzzy number to be greater than $k$ convex fuzzy numbers $M_{i}(i=1,2, \ldots, k)$ can be defined by

$$
\begin{array}{r}
V\left(M \geq M_{1}, M_{2}, \ldots, M_{k}\right)=V\left[\left(M \geq M_{1}\right) \text { and }(M \geq\right. \\
\left.M_{2}\right) \text { and } \ldots\left(M \geq M_{k}\right)=\operatorname{minV}\left(M \geq M_{i}\right) \\
i=1,2, \ldots, k
\end{array}
$$

Assume that

$$
\dot{d}\left(A_{i}\right)=\min \left(S_{i} \geq S_{k}\right)
$$

For $k=1, \ldots, n ; k \neq i$ the the weight vector is given by

$$
\dot{W}=\left(\dot{d}\left(A_{1}\right), \dot{d}\left(A_{2}\right), \ldots, \dot{d}\left(A_{n}\right)\right)^{T}
$$

where $A_{i}(i=1,2 \ldots n)$ are $n$ elements.

Via normalization, we get the normalized weight vectors

$$
W=\left(d\left(A_{1}\right), d\left(A_{2}\right), \ldots, d\left(A_{n}\right)\right)^{T}
$$

where $\mathrm{W}$ is a no fuzzy number.

\section{RESEARCH METHODOLOGY AND DATA COLLECTION}

Data gathered via questionnaire survey. The questionnaire contains proposed CSF indicators and their criteria. The questionnaires were distributed among sample e-learners and ask them for comparing the importance of each CSF indicator to another one and compare the importance of each criterion under each indicator to the other one at the same indicator. The scale used in this questionnaire is presented in table 2. Surveys were sent to 235 e-learners in 4 universities offering e-learning courses via email which 200 of them were received back. So the respond rate is approximately $85 \%$. To calculate the final score of each indicator and criterion, the arithmetic operations between triangular fuzzy numbers is used. Then answers are analyzed by FAHP method. To simplify calculations a FAHP program which is developed by the authors is applied.

\section{FINDINGS}

The final score of the pair-wise comparison among indicators and among criteria are input to the FAHP software developed by the authors. Figure 1 shows the pair-wise comparison matrix related to the "Student Characteristics". The final weights of criteria and indicators are summarized in tables 3, 4, 5, 6, 7, 8, 9and10.

TABLE 2: THE FAHP QUESTIONNAIRE SCALE USED FOR PAIRWISE COMPARISON

\begin{tabular}{|l|l|l|}
\hline$(1,1,1)$ & E & Equal \\
\hline$\left(\frac{1}{2}, 1, \frac{3}{2}\right)$ & EI & Equally Important \\
\hline$\left(1, \frac{3}{2}, 2\right)$ & WMI & Weakly More Important \\
\hline$\left(\frac{3}{2}, 2, \frac{5}{2}\right)$ & SMI & Strongly More Important \\
\hline$\left(2, \frac{5}{2}, 3\right)$ & VSMI & Very strongly More Important \\
\hline$\left(\frac{5}{2}, 3, \frac{7}{2}\right)$ & AMI & Absoloutly More Important \\
\hline
\end{tabular}

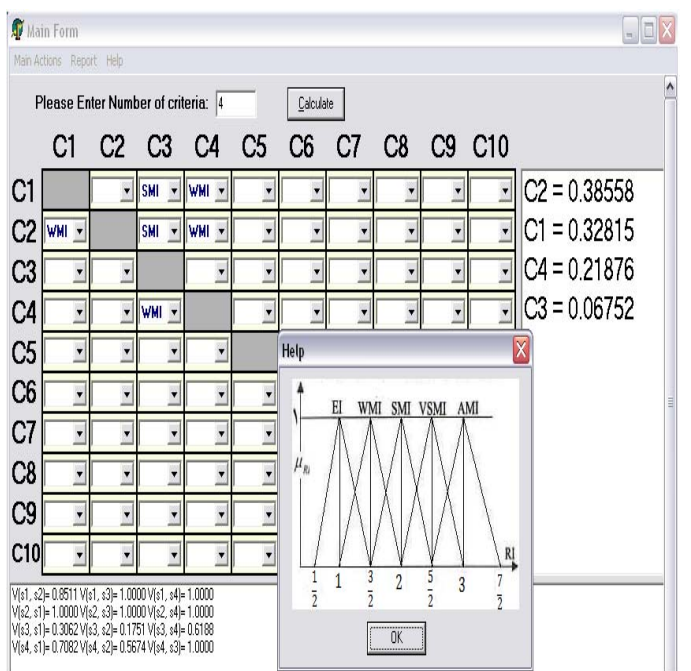

Fig. 1.the software output of FAHP calculation related to Student Characteristics.

TABLE3: THE WeIghtS OF THE CRITERIA UNDER StUDENT CHARACTERISTICS.

\begin{tabular}{|l|l|l|}
\hline Items & Criteria & weights \\
\hline C1 & Computer skill & 0.32815 \\
\hline C2 & Motivation & 0.38558 \\
\hline C3 & Commitment & 0.06752 \\
\hline C4 & Learning speed & 0.21876 \\
\hline
\end{tabular}

TABLE4: WEIGHT OF THE CRITERIA UNDER INSTRUCTOR CHARACTERISTICS.

\begin{tabular}{|l|l|l|}
\hline Items & Criteria & weights \\
\hline C1 & Instructor attitude to students & 0.310165 \\
\hline C2 & Instructor attitude to e-learning & 0.18552 \\
\hline C3 & Computer skill & 0.504315 \\
\hline
\end{tabular}

TABLE5: WEIGHT OF THE CRITERIA UNDER CONTENT QUALITY.

\begin{tabular}{|l|l|c|}
\hline Items & Criteria & Weights \\
\hline C1 & Update content & 0.36879 \\
\hline C2 & Sufficient content & 0.26356 \\
\hline C3 & Understandable content & 0.36765 \\
\hline
\end{tabular}

TABLE6: WEIGHT OF THE CRITERIA UNDER INFORMATION TECHNOLOGY QUALITY.

\begin{tabular}{|r|l|l|}
\hline Items & Criteria & weights \\
\hline C1 & Reliability & 0.14132 \\
\hline C2 & Accessibility & 0.16798 \\
\hline C3 & Degree of guidance & 0.21186 \\
\hline C4 & Design of user interface & 0.09665 \\
\hline C5 & Network security & 0.12052 \\
\hline C6 & Timeliness & 0.26167 \\
\hline
\end{tabular}


TABLE7: WEIGHT OF THE CRITERIA UNDER PARTICIPATION INTERACTION.

\begin{tabular}{|c|l|l|}
\hline Items & Criteria & weights \\
\hline $\mathrm{C} 1$ & Learning community & 0.68421 \\
\hline $\mathrm{C} 2$ & Ease of interaction with together & 0.31579 \\
\hline
\end{tabular}

TABLE8: WEIGHT OF THE CRITERIA UNDER EDUCATIONAL INSTITUTES SUPPORT.

\begin{tabular}{|c|l|l|}
\hline Items & Criteria & weights \\
\hline $\mathrm{C} 1$ & Providing financial support & 0.68421 \\
\hline $\mathrm{C} 2$ & Proper feedback & 0.31579 \\
\hline
\end{tabular}

TABLE9: WEIGHT OF THE CRITERIA UNDER KM.

\begin{tabular}{|c|l|l|}
\hline Items & Criteria & weights \\
\hline $\mathrm{C} 1$ & Degree of applying knowledge & 1 \\
\hline & management tools & \\
\hline
\end{tabular}

TABLE10: WEIGHT OF THE SEVEN MAJOR CSFS

\begin{tabular}{|l|l|l|}
\hline Items & Criteria & weights \\
\hline C1 & student characteristics & 0.24456 \\
\hline C2 & IT quality & 0.21747 \\
\hline C3 & instructor characteristics & 0.19169 \\
\hline C4 & content quality & 0.13361 \\
\hline C5 & Educational institutes support & 0.11283 \\
\hline C6 & participation interaction & 0.05612 \\
\hline C7 & KM & 0.04372 \\
\hline
\end{tabular}

The final ranking of the CSF of e-learning systems and their criteria are summarized in figure (2).

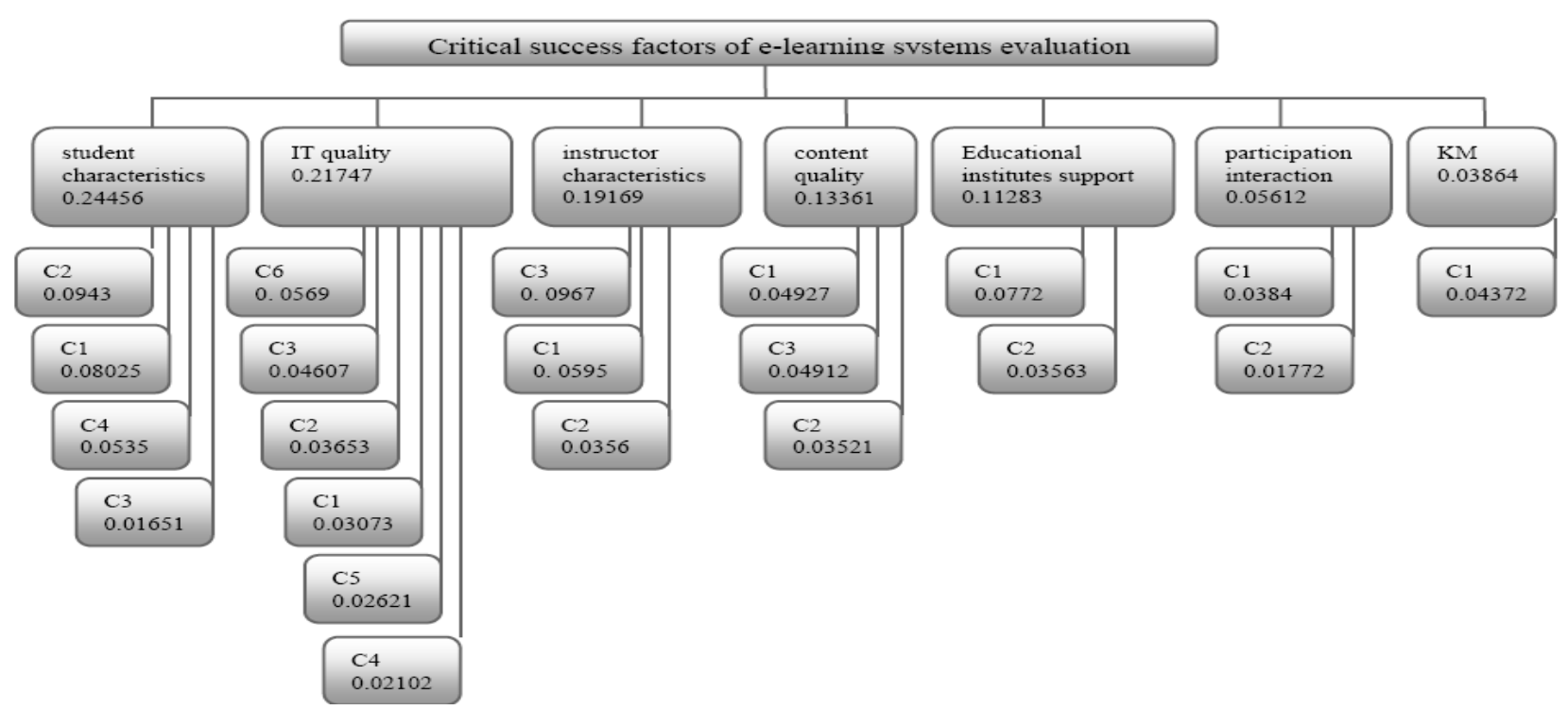

Fig .2. the final ranking of the critical success factors and their criteria for e-learning systems evaluation

\section{CONCLUSION}

By regarding dynamic and changing environment, successful educational organizations and institutes are those who manage and integrate learning systems continuously to gain learning objects and superior performance. The emergence of e-learning has brought vitality to traditional teaching, because it has a great advantage in knowledge transformation, classroom teaching, social interaction. This paper proposes an approach based on the FAHP and CSF for evaluating the performance of e-learning. The analytic hierarchy is structured by the seven major CSFs including Instructor characteristics, Student characteristics, Content quality, Information technology quality, Participations Interaction, Educational institutes support, Knowledge management followed by sub categories of CSFs.

The results show that student characteristics and IT quality have higher weightings and instructor characteristics, content quality, educational institutes support, participation interaction and $\mathrm{KM}$ are in the next priorities of importance. For sub measures, "computer skills" and "motivation" of students as well as "providing financial support from educational institutes" are the most important factors to be focused on. A prioritized list of CSFs was used to guide vendors to design and develop better systems and also assist managers to improve and justify existing e-learning systems. This approach for evaluation provides opportunity for educational institutes and universities to concentrate on key issues and it can also offer beneficial information in strategic planning of e-learning initiatives.

\section{REFERENCE}

[1] A. Keramati, M. Afshari-Mofrad and A. Kamrani, "The role of readiness factors in E-learning outcomes: An empirical study", Computers \& Education., Vol. 57, pp. 1919-1929, 2011.

[2] M.R. Martinez-Torres, S.L.Toral and F. Barrero, "Identification of the design variables of eLearning tools", interacting with computers, Vol. 23,pp. 279-288, 2011.

[3] H. Selim, "Critical success factor for e-learnnig acceptance: confirmatory factor models", computers \& Education, Vol. 49, pp. 396-413, 2007.

[4] A. Baylari, Gh. Montazer, "Design a personalized e-learning system based on item response theory and artificial neural network approach", Expert systems with applications, Vol. 36, pp. 8013-8021, 2009.

[5] M. Hogo, "Evaluation of e-learning systems based on fuzzy clustering models and statistical tools", Expert systems with applications, Vol. 37, pp. 6891-6903, 2010.

[6] P. Sun, R. Tsai, G. Finger and Y. Chen, "What drives a successful e-learning? An empirical investigation of the critical factors influencing learner satisfaction", Computers \& Education, Vol. 50, pp. 1183-1202, 2008.

[7] M. Mosakhani and M. Jamporazmey, "Introduce Critical Success Factors (CSFs) of Elearning for Evaluating Elearning Implementation Success", International Conference on Educational and Information Technology, V1-224-V1-228, 2010.

[8] R. Johnson, H. Gueutalb and C. Falbe, "Technology, trainees, metacognitive activity and e-learning effectiveness", Journal of managerial psychology, Vol.24, pp. 545-566, 2009.

[9] J. Ireland, H. Correia and T. Griffin, "Developing quality in e-learning: a framework in three parts", Quality assurance in Education, Vol. 17, No. 3, pp. 250-263, 2009.

[10] Y. Wang, H. Wang and D. Shee, "Measuring e-learning systems success in an organizational context: Scale development and 
validation", Computers in humman behavior, Vol. 23, pp. 1792-1808, 2007.

[11] A. Strand, T. Thune, "E-learning policies, practices and challenges in two Norwegian organizations", Evaluation and program planning, Vol 26, pp.185-192, 2003.

[12] S. Ozkan and R. Koseler, "Multi-dimentional students evaluation of e-learning systems in the higher education context: An empirical investigation”, Computer \& Education, Vol. 53, pp. 1285-1296, 2009.

[13] T. Volery and D. Lord "Critical success factors in online education", The International Journal of Educational Management, Vol. 14, No. 5, pp. 216-223, 2000.

[14] M. Bonito, F. Figueiredo, A. Martins and J. Jorge, "An integrated evaluation method for e-learning: a case study", Interactive Technology \& Smart education, Vol. 1, pp. 59-68, 2006.

[15] V. A. Thurmond, K. Wambach and H. R. Connors, "Evaluation of student satisfaction: determining the impact of a web-based environment by controlling for student characteristics", The American Journal of Distance Education, Vol. 16, pp.169-189, 2002.

[16] A. Lau and E. Tsui, "Knowledge management perspective on e-learning effectiveness", Knowledge-Based Systems, Vol. 22, pp. 324-325, 2009.

[17] B. Soong, H. Chan, B. Chua and K. Loh, "Critical success factors for on-line course resources", Computers \& Education, Vol. 36, pp.101-120, 2001.

[18] G. Piccoli, R. Ahmad and B. Ives, "Web-based virtual learning environments: a research framework and a preliminary assessment of effectiveness in basic IT skills training", MIS Quarterly, Vol. 25, pp. 401-426, 2001.
[19] C.L. Dillon and C.N. Guawardena, "A framework for the evaluation of telecommunications-based distance education", Paper presented at the 17th Congress of the International Council for Distance Education, Open University, Milton Keynes, 1995.

[20] T. Govindasamy, "Successful implementation of e-learning; pedagogical considerations", The Internet and Higher Education, Vol. 4, No.(3-4), pp. 287-299, 2002.

[21] D. Shee and Y. Wang, "Multi-criteria evaluation of the web-based e-learning system: A methodology based on learner satisfaction and its applications", Computer \& Education, Vol. 50, pp. 894-905, 2008.

[22] L. A. Zadeh, "Fuzzy sets. Information and Control", Vol. 8, pp. 338-353, 1965.

[23] A. Kumar, J. Kaur and P. Singh, "A new method for solving fully fuzzy linear programming problems", Applied Mathematical Modeling, Vol. 35, pp. 817-823, 2011.

[24] D. Y. Chang, "Applications of the extent analysis method on fuzzy AHP", European Journal of Operational Research., Vol. 95, pp. 649-655, 1996.

[25] T. L. Saaty, "The analytic hierarchy process", New York: McGraw-Hill, 1980.

[26] D.Y. Chang, "Extent Analysis and Synthetic Decision", Optimization Techniques and Applications. ( $1^{\text {st }}$ ed). Singapore: World Scientific, $352,1992$.

[27] M. Shank, A. Boynton and R. Zmud, "Critical Success Factor Analysis as a Methodology for MIS Planning”, MIS Quarterly, Vol. 9, No. 2, pp. 121-129, 1985. 